\title{
Article
}

\section{Synthesis of Sub-100 nm Glycosylated Nanoparticles via a One Step, Free Radical, and Surfactant Free Emulsion Polymerization}

\author{
Lunn, Andrew and Perrier, Sebastien
}

Available at http://clok.uclan.ac.uk/28419/

Lunn, Andrew ORCID: 0000-0003-2884-2755 and Perrier, Sebastien (2018) Synthesis of Sub-100 nm Glycosylated Nanoparticles via a One Step, Free Radical, and Surfactant Free Emulsion Polymerization. Macromolecular Rapid Communications, 39 (19). ISSN 1022-1336

It is advisable to refer to the publisher's version if you intend to cite from the work. http://dx.doi.org/10.1002/marc.201800122

For more information about UCLan's research in this area go to http://www.uclan.ac.uk/researchgroups/ and search for <name of research Group>.

For information about Research generally at UCLan please go to http://www.uclan.ac.uk/research/

All outputs in CLoK are protected by Intellectual Property Rights law, including Copyright law. Copyright, IPR and Moral Rights for the works on this site are retained by the individual authors and/or other copyright owners. Terms and conditions for use of this material are defined in the policies page. 
Original citation:

Lunn, Andrew M. and Perrier, Sébastien (2018) Synthesis of sub-100 nm glycosylated nanoparticles via a one step, free radical, and surfactant free emulsion

polymerization. Macromolecular Rapid Communications doi: $10.1002 / m a r c .201800122$

\section{Publisher's statement:}

"This is the peer reviewed version of the Lunn, Andrew M. and Perrier, Sébastien (2018) Synthesis of sub-100 nm glycosylated nanoparticles via a one step, free radical, and surfactant free emulsion polymerization. Macromolecular Rapid Communications doi:10.1002/marc.201800122 which has been published in final form doi: http://doi.org/10.1002/marc.201800122

This article may be used for non-commercial purposes in accordance with Wiley Terms and Conditions for Self-Archiving." 
1 Synthesis of Sub 100 nm Glycosylated-Nanoparticles via a One Step, Free Radical and Surfactant Free

2 Emulsion Polymerisation

3 Andrew M. Lunn ${ }^{1}$ and Sébastien Perrier ${ }^{1,2,3, *}$

$4{ }^{1}$ Department of Chemistry, the University of Warwick, Gibbet Hill, Coventry, CV4 7AL, UK

$5 \quad{ }^{2}$ Warwick Medical School, University of Warwick, Coventry, CV4 7AL, UK

$6 \quad{ }^{3}$ Faculty of Pharmacy and Pharmaceutical Sciences, Monash University, 381 Royal Parade, Parkville, VIC 7 3052, Australia.

8

9 e-mail: $\underline{\text { S.Perrier@warwick.ac.uk }}$

13 Abstract

14 We present the facile synthesis of sub $100 \mathrm{~nm}$ glyco-nanoparticles via a one-step, free radical and surfactant 15 free emulsion polymerisation. We show that by using sterically large, hydrophilic glycomonomers such as a 16 lactose acrylamide with the charged azo initiator 4,4'-azobis(4-cyanovaleric acid) (ACVA), growing particles 17 are stabilised enough to reproducibly produce well defined (PDi $\leq 0.1$ ) glycoparticles with diameters below $18100 \mathrm{~nm}$.

20 Keywords: Emulsion polymerisation, glyco-nanoparticle, surfactant free 
24 Emulsion polymerisation is an industrially favoured technique for synthesising many types of polymers due 25 to its favourable kinetics, the high specific heat capacity of water and the low viscosity of the final polymer 26 product $^{[1]}$. One major use of emulsion polymerisation is the facile synthesis of functional polymer

nanoparticles. ${ }^{[2-6]}$ A classic emulsion polymerisation uses a surfactant, such as sodium dodecyl sulphate, to provide nucleation sites for growing "z-mer" polymer chains and particle stabilisation. Without the addition of surfactant to the system, a "self-nucleating" emulsion polymerisation, which will produce both latex particles and linear hydrophilic polymer in solution, typically produces particles in the hundreds of nanometres to micron diameters. ${ }^{[7-13]}$ Latexes with particles under $100 \mathrm{~nm}$ in diameter are desirable however for applications such as drug delivery, to, for example, take advantage of the tumour targeting enhanced permeability and retention (EPR) effect. ${ }^{[14-16]}$ However, particles made using a surfactant must then be extensively dialysed to remove the surfactant for use in applications such as drug delivery and photonics. ${ }^{[11,}$ ${ }^{17,18]}$ There has therefore been a large amount of research into synthesising functional nanoparticles with diameters under $100 \mathrm{~nm}$ using "surfactant free" controlled radical polymerisation. ${ }^{[2,19-25]}$ One such technique is reversible addition-fragmentation chain transfer (RAFT) emulsion polymerization, in which a short amphiphilic di-block copolymer is prepared, then suspended in water to act as a surfactant for the emulsion polymerisation. The initial di-block subsequently becomes bound to the resulting latex particle via chain extension, conveniently imparting functionality from the hydrophilic section onto the resulting latex and avoiding the need for dialysis. ${ }^{[24,26,27]}$ Such a synthetic approach can be time consuming and expensive when compared to standard emulsion polymerization, ${ }^{[28]}$ although it allows access to a variety of functionalised particles with diameters below $100 \mathrm{~nm} \cdot{ }^{[29,30]}$ Nano-particles that are functionalised on their surface are also of particular interest in applications such as targeted drug delivery. ${ }^{[14,17,30-35]}$ In particular, specific sugar moieties can be positioned at the surface of the particles, to target a class of protein receptors known as lectins. Previous research into using sugar-lectin targeting for drug delivery has shown that presenting the targeting sugar in a high concentration, such as that on the surface of a particle, increases the targeting efficiency of a drug delivery vector, taking advantage of the "glycocluster effect". ${ }^{36,37]}$ Recent developments in this area have applied the principle of targeting lectins with glycopolymers in more refined systems, using sequenced defined polymers alone and in combination with stimuli responsive polymers to elicit a more specific 
51 biological targeting. ${ }^{[37-41]}$ Amongst the many stimuli responsive systems reported, poly $(N-$

52 isopropylacrylamide) is commonly used for temperature response, where heating above the cloud point of the

53 system triggers a self-assembly or reveals a glycopolymer. ${ }^{[42,43]}$ Next to temperature, $\mathrm{pH}$ is arguably one of

54 the most ubiquitously exploited stimuli, used to induce glycopolymer assembly and disassembly, or to release 55 a covalently bound drug molecule via an acid cleavable linker; these amongst many other unique systems 56 represent a growing and active field of research in drug delivery. ${ }^{[44-47]}$

Given their great potential, and current synthetic problems, it is therefore desirable to be able to synthesise functional polymer latex particles, under $100 \mathrm{~nm}$ in diameter with a low-cost and fast, one step synthesis that does not require further purification.

\section{Results and Discussion}

The full synthetic procedure for particle synthesis can be found in the supporting information. In brief: monomers and initiator were dissolved or suspended in water within a glass vial. This system was then, under an inert atmosphere, rigorously agitated with a magnetic follower at $800 \mathrm{RPM}$ and heated to $70{ }^{\circ} \mathrm{C}$ for three hours. In all cases this resulted in the formation of well-defined nanoparticles (Pdi $\leq 0.1)$, ranging in size from 50-350 nm (Table 1), which when broken up into constituent polymeric unimers, along with linear polymer in solution, showed dispersities as determined by GPC between 1.5-1.8 (SI: S2), and over 99\% monomer conversion, determined by ${ }^{1} \mathrm{H}$ NMR (SI: S3).

\begin{tabular}{|c|c|c|c|c|c|c|c|}
\hline & $\begin{array}{l}\text { Composition of Free } \\
\text { Radical Particle }\end{array}$ & $\begin{array}{r}\text { Hydrophilic } \\
(\mu \mathrm{mol})\end{array}$ & $\begin{array}{r}\text { Hydrophobic } \\
(\mu \mathrm{mol})\end{array}$ & $\begin{array}{r}\zeta \text { - Potential } \\
(\mathrm{mV})\end{array}$ & $\begin{array}{r}\text { Diameter by } \\
\text { DLS (nm) }\end{array}$ & $\mathbf{P D i}^{\mathbf{a}}$ & $\begin{array}{r}\text { Diameter by } \\
\text { SEM (nm) }\end{array}$ \\
\hline$\overline{\mathbf{A}}$ & $\mathrm{P}(\text { LactAm })_{1}-\mathrm{co}-(\text { sty })_{5}$ & 4.711 & 23.55 & -37.1 & 55 & 0.048 & 54 \\
\hline $\mathbf{B}$ & $\mathrm{P}(\mathrm{PEGA})_{1}-c o-(\text { sty })_{5}$ & 4.711 & 23.55 & -20.4 & 70 & 0.074 & 69 \\
\hline $\mathbf{C}$ & $\mathrm{P}(\mathrm{ManAm})_{1}-\mathrm{co}-(\text { sty })_{5}$ & 4.711 & 23.55 & -14.8 & 88 & 0.02 & 103 \\
\hline D & $\mathrm{P}(\mathrm{HEAm})_{1}-$ co-(sty $)_{5}$ & 4.711 & 23.55 & -39.2 & 112 & 0.057 & 117 \\
\hline $\mathbf{E}$ & $\mathrm{P}($ sty $)$ & N/A & 23.55 & -37.3 & 108 & 0.063 & 106 \\
\hline $\mathbf{F}$ & $\mathrm{P}(\mathrm{LactAm})_{1}-\mathrm{co}-(\mathrm{BA})_{5}$ & 22.8 & 114 & -31.3 & 85 & 0.1 & - \\
\hline $\mathbf{G}$ & $\mathrm{P}(\mathrm{Lact} A \mathrm{~m})_{1}-\mathrm{co}-(\mathrm{BA})_{10}$ & 22.8 & 228 & -38.1 & 198 & 0.058 & - \\
\hline $\mathbf{H}$ & $\mathrm{P}(\mathrm{LactAm})_{1}-c o-(\mathrm{BA})_{20}$ & 22.8 & 456 & -43 & 260 & 0.051 & - \\
\hline $\mathbf{I}$ & $\mathrm{P}(\text { LactAm })_{1}-c o-(\mathrm{BA})_{30}$ & 22.8 & 684 & -37.3 & 256 & 0.06 & - \\
\hline $\mathbf{J}$ & $\mathrm{P}(\mathrm{Lact} A m)_{1}-c o-(\mathrm{BA})_{50}$ & 22.8 & 1140 & -43.4 & 348 & 0.064 & - \\
\hline
\end{tabular}

Table 1: Characterisation for all polymer particles synthesised with surfactant free emulsion polymerisation. All polymerisations used an ACVA initiator concentration of $3.13 \times 10^{-6} .{ }^{\text {a }}$ Determined using equation S1, see Supporting Information 
Having optimised a one pot, single step method to produce nanoparticles, the effect of varying the

hydrophilic monomer was investigated. It is proposed that in the early stages of this synthesis, hydrophilic homopolymer is predominantly formed (as it is fully soluble in the water phase with the initiator), which is then followed by the separate formation short copolymers with the small amount of hydrophobic monomer in solution. The copolymers formed then act as a surfactant to drive an emulsion mechanism, where nucleated particles are stabilised by the initiator and hydrophilic polymer, growing by both polymerisation and particle aggregation. ${ }^{[1,48]}$ As such, the choice of hydrophilic monomer used should have a large impact on the size of the resulting particle. To test this, the hydrophilic monomer was varied, whilst keeping all other reaction conditions the same. Lactose acrylamide (LactAm), mannose acrylamide (ManAM), hydroxyethyl acrylamide (HEAm) and poly(ethylene glycol) acrylate (PEGA) were employed, in order to assess the effect of monomer size and hydrophilicity. The same synthesis was also performed using no hydrophilic monomer, but with the negatively charged 4,4'-azobis(4-cyanovaleric acid) (ACVA) initiator as hydrophilic component. The polymerisation led to a range of particles which size varied from largest to smallest in the order: HEAm $\geq$ ACVA $>$ Mannose > PEGA $>$ Lactose (Table 1, S4 and S5), confirming that the hydrophilic monomer used plays a large part in the stabilisation of this emulsion system and can be used to influence the size of any resulting particle.

We hypothesise that monomers with greater steric hindrance, charge, and/or water solubility, give greater stabilisation, thus producing smaller particles, as they have a lower apparent number of aggregation. It is also noteworthy that emulsion polymerisation with only the ACVA initiator as the hydrophilic component produced well defined particles of $108 \mathrm{~nm}$ diameter (as established by DLS). We expect the stabilisation in this case is due to the charged carboxylic acid group of ACVA having been deprotonated by sodium hydroxide to ensure aqueous solubility, showing the importance of the initiator in stabilising the growing latex particles. ${ }^{[13,49]}$ In the case of the HEAm particles, the initiator potentially provided the majority of the particle stabilisation, as both the HEAm and ACVA-only particles were of an equivalent size and zeta potential. Lactose acrylamide produced the smallest particles $55 \mathrm{~nm}$ in diameter (determined by DLS and confirmed by SEM, giving an average size of $54 \mathrm{~nm}$ ) (Figure 1). This suggested that lactose acrylamide provides superior stabilisation when compared to all other hydrophilic co-monomers tested, due to its 7 hydroxyl groups, which 

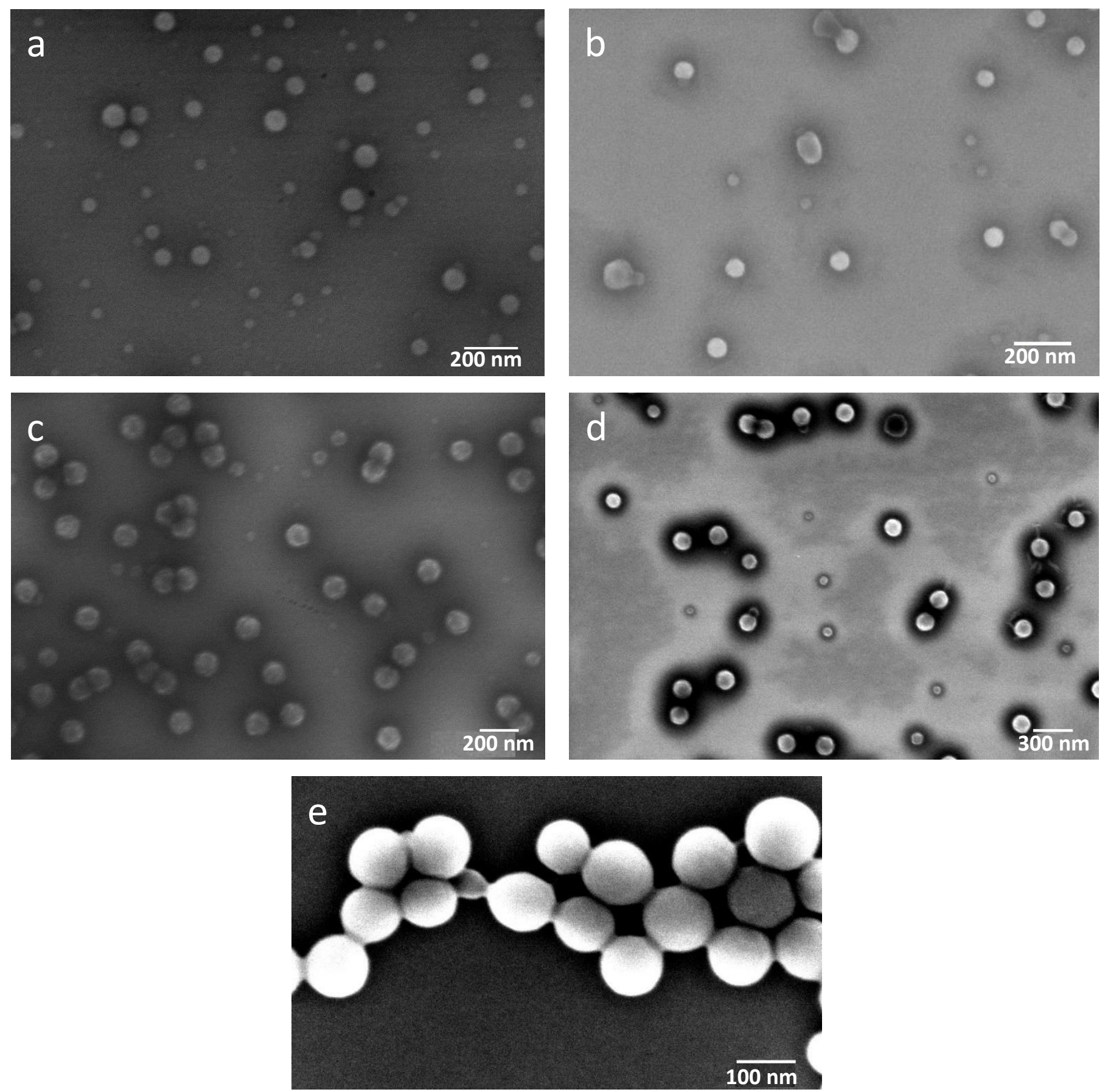

Figure 1: SEM images showing particle size and morphology. Pictures a, b, c, d and e correspond to styrene particles with shells of lactose acrylamide, PEGA, mannose acrylamide, hydroxyethyl acrylamide and no hydrophilic monomer respectively. Average diameter for each in table 1

increase its number of hydration and water solubility, as well as good steric stabilisation from its bulky disaccharide structure. These results are remarkable as surfactant-free polymerisation does not typically provide access to particle diameters under $100 \mathrm{~nm}$, due to insufficient stabilisation which causes particle aggregation. Indeed, most examples to date use the initiator potassium persulfate (KPS) to provide sufficient stabilisation, e.g. in the emulsion polymerisation of styrene and methyl methacrylate. ${ }^{[13,50]}$ In this work, we show that styrene particles made with ACVA initiator and either lactose acrylamide, PEGA or mannose acrylamide as a co-monomer provide access to particles of diameter 55, 70 and $88 \mathrm{~nm}$ respectively. Being 
able to reliably produce particles under $100 \mathrm{~nm}$ in diameter without the use of a surfactant or initial polymer diblock shows the potential for using a charged initiator with sterically large or charged monomers, particularly glycomonomers, for their ability at stabilising a latex and to produce functional nanoparticles.

The surface functionality of the particles was assessed by a turbidimetric aggregation test between mannose coated particles ("particle C" Table 1), and the lectin concanavalin A (Con A), which is known to bind preferentially to mannose and glucose. ${ }^{[37,51,52]}$ Latex was mixed in a UV-Vis spectrometer with a $1.3 \mu \mathrm{M}$ solution of Con A in TRIS buffer at $\mathrm{pH} \mathrm{7,} \mathrm{and} \mathrm{the} \mathrm{absorbance} \mathrm{tracked} \mathrm{at} 500 \mathrm{~nm}$ (Figure 2). This test was performed before and after removing any free sugar homopolymer in solution by precipitating the particles out of suspension using centrifugation for ten minutes at 13,500 rpm, and re-suspending the particle pellet in de-ionised water, a process repeated three times. This purification technique was preferred to dialysis, as it ensured that even the longest free radical polymer not anchored to the particle was removed, as there is no upper molecular weight cut off, which is necessary when purifying using a dialysis membrane.
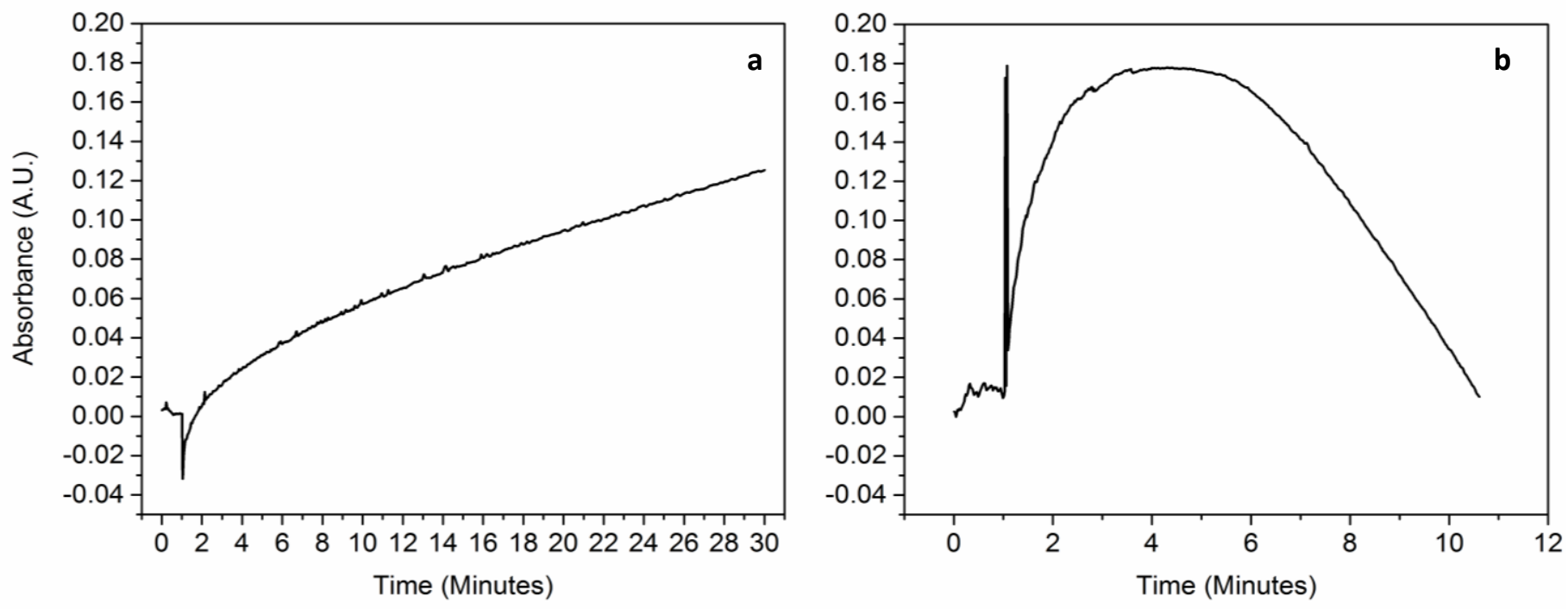

Figure 2: UV-Vis turbidimetric aggregation tests between mannose coated particles and concanavalin A. a) raw latex with free glycopolymer in solution b) purified latex with free glycopolymer removed from solution via centrifugation

The results showed a very slow increase in absorbance over 30 minutes when the raw latex was mixed with a Con A solution. However, when the same test was performed on the purified latex, a much faster increase in absorbance, and subsequent reduction (due to large particulate aggregates sedimenting out of solution), was observed over 11 minutes. We hypothesise that the reduced response from the raw latex is due 
have a covalently bound glycopolymer shell. A modified turbidimetric test was also performed with the

addition of free mannose post-aggregation in excess to compete for ConA binding sites and induce aggregate break up, confirming that aggregation was due to sugar-lectin binding (SI: S6). Gravimetry was also used to quantify the amount of hydrophilic glycopolymer bound to the surface of the particles. The mass of $1 \mathrm{~mL}$ of raw latex was compared to that of $1 \mathrm{~mL}$ the purified latex, after drying both solution in a vacuum oven at 40 ${ }^{\circ} \mathrm{C}$ for 16 hours. The average difference in mass after three repeats represented the mass of polymer in solution, and was used differentially to determine the amount of polymer bound to the particles, $41 \%$ of the polymer.

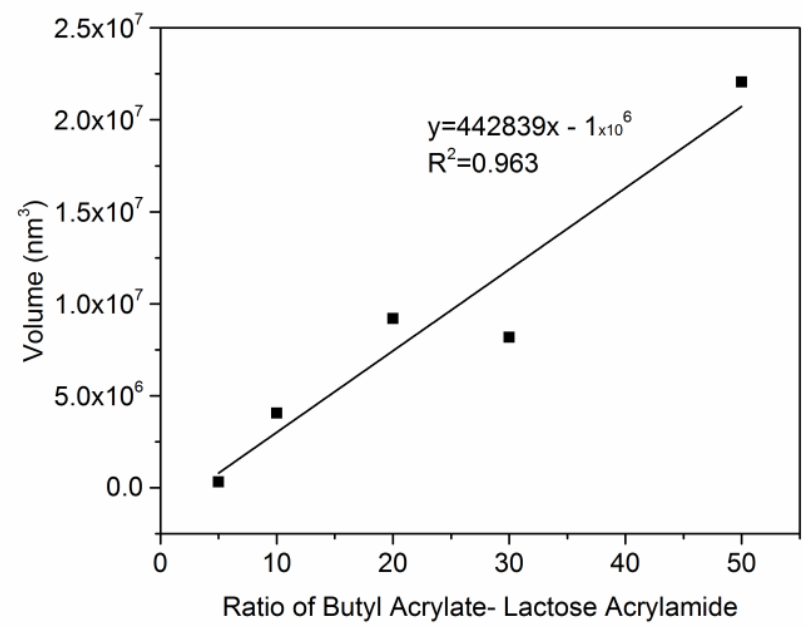

Figure 3: Particle size calibration with varying molar ratios of hydrophilic lactose acrylamide monomer to hydrophobic butyl acrylate monomer plotted against the resulting particle volume

To determine if this emulsion process can reliably control particle size over a larger range, and be used with a different hydrophobic monomer, five latexes with varying ratios of lactose acrylamide to butyl acrylate were synthesised and the monomer ratios plotted against the resulting particle volume. The results (Table 1 and Figure 3) show that by varying the ratio of lactose acrylamide: butyl acrylate from 1:5 to 1:50, the diameter of the resulting particle could be reliably adjusted to between 85 and $348 \mathrm{~nm}\left(321,555-22,066,629 \mathrm{~nm}^{3}\right)$, with a linear relationship between hydrophobic component and resulting volume. Particle diameters under 100 nm were also produced with butyl acrylate, showing the ability of this method to produce functionalised nanoparticles with monomers other than styrene. To further explore the limits of our system, we experimentally determined the maximum particle concentration possible using this synthetic method at 15-20 $\mathrm{wt} \%$ of monomer. This was determined by varying the total solid content of the emulsion whilst maintaining a molar ratio of 1:10 lactose acrylamide to styrene. Well-defined particles were produced up to $15 \mathrm{wt} \%$ of 
monomer (SI: S7). At $20 \mathrm{wt} \%$ and above, defined particles were not obtained and formed aggregated to such

151 an extent that a reliable size was not obtainable by DLS.

\section{Conclusion}

153 We have shown that a surfactant free emulsion can reliably produce nanoparticles between $50-350 \mathrm{~nm}$ in 154 diameter in a one-step synthesis, with little or no purification. The initiator ACVA and glycomonomers, 155 particularly disaccharide monomers with a large number of hydration such as lactose acrylamide, are extremely good at stabilising emulsion polymerisations and provide a useful tool for synthesising low 157 diameter, well defined carbohydrate coated nanoparticles suitable for biological use.

\section{Acknowledgments}

The Royal Society Wolfson Merit Award (WM130055; S.P.) and the Monash-Warwick Alliance (A.M.L.; S.P.), are acknowledged for financial support.

\section{Table of Contents Summary Text}

A rapid one-step approach to synthesising sub-100 $\mathbf{n m}$ polymeric glyco-nanoparticles without the use of a surfactant is presented. The free radical method takes advantage of the exceptional ability of glycomonomers, particularly lactose acrylamide to stabilise a growing latex particle, with the use of the charged initiator ACVA to go from monomer to final latex in under three hours.

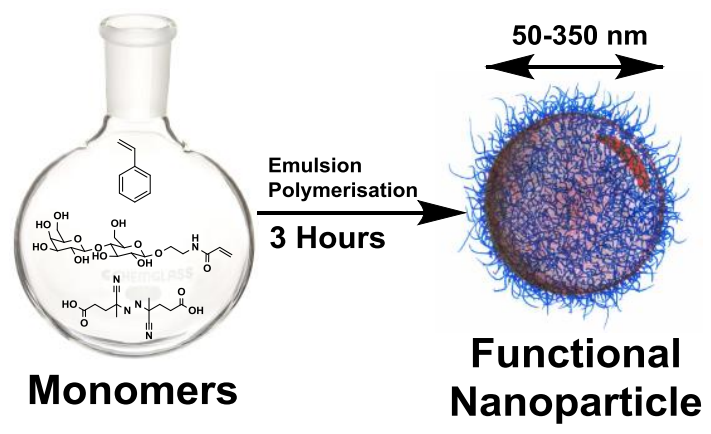


[1] R. M. Fitch, "Polymer colloids", Academic Press, 1997.

[2] N. P. Truong, J. F. Quinn, A. Anastasaki, M. Rolland, M. N. Vu, D. M. Haddleton, M. R. Whittaker, T. P. Davis, Polymer Chemistry 2017, 8, 1353.

[3] S. S. Ting, E. H. Min, P. B. Zetterlund, M. H. Stenzel, Macromolecules 2010, 43, 5211.

[4] C. J. Ferguson, R. J. Hughes, D. Nguyen, B. T. Pham, R. G. Gilbert, A. K. Serelis, C. H. Such, B. S. Hawkett, Macromolecules 2005, 38, 2191.

[5] P. Gurnani, A. M. Lunn, S. Perrier, Polymer 2016, 106, 229.

[6] G. Delaittre, J. Nicolas, C. Lefay, M. Save, B. Charleux, Chem. Commun. 2005, 614.

[7] K. Tauer, R. Deckwer, I. Kühn, C. Schellenberg, Colloid Polym. Sci. 1999, 277, 607.

[8] C. Chern, S. Lin, S. Chang, J. Lin, Y. Lin, Polymer 1998, 39, 2281.

[9] M. S. D. Juang, I. M. Krieger, Journal of Polymer Science Part A: Polymer Chemistry 1976, 14, 2089.

[10] J. Appel, S. Akerboom, R. G. Fokkink, J. Sprakel, Macromol. Rapid Commun. 2013, 34, 1284.

[11] Z. Luo, C. Zou, S. Syed, L. A. Syarbaini, G. Chen, Colloid Polym. Sci. 2012, 290, 141.

[12] A. M. Telford, B. T. Pham, C. Neto, B. S. Hawkett, Journal of Polymer Science Part A: Polymer Chemistry 2013, 51, 3997.

[13] A. Goodall, M. Wilkinson, J. Hearn, Journal of Polymer Science Part A: Polymer Chemistry 1977, 15, 2193.

[14] A. M. Eissa, A. Abdulkarim, G. J. Sharples, N. R. Cameron, Biomacromolecules 2016, 17, 2672.

[15] H. Maeda, J. Wu, T. Sawa, Y. Matsumura, K. Hori, J. of Controlled Release 2000, 65, 271.

[16] J. Fang, H. Nakamura, H. Maeda, Adv. Drug Delivery Rev. 2011, 63, 136.

[17] A. Mahapatro, D. K. Singh, Journal of nanobiotechnology 2011, 9, 55.

[18] J. D. Robertson, L. Rizzello, M. Avila-Olias, J. Gaitzsch, C. Contini, M. S. Magoń, S. A. Renshaw, G. Battaglia, Scientific Reports 2016, 6, 27494.

[19] C. Dire, S. Magnet, L. Couvreur, B. Charleux, Macromolecules 2008, 42, 95.

[20] J. Rieger, W. Zhang, F. o. Stoffelbach, B. Charleux, Macromolecules 2010, 43, 6302.

[21] M. Siauw, B. S. Hawkett, S. Perrier, Journal of Polymer Science Part A: Polymer Chemistry 2012, 50, 187.

[22] J. Ulama, M. Zackrisson Oskolkova, J. Bergenholtz, The Journal of Physical Chemistry B 2014, 118, 2582.

[23] S. A. Bon, M. Bosveld, B. Klumperman, A. L. German, Macromolecules 1997, 30, 324.

[24] C. J. Ferguson, R. J. Hughes, D. Nguyen, B. T. Pham, R. G. Gilbert, A. K. Serelis, C. H. Such, B. S. Hawkett, Macromolecules 2005, 38, 2191.

[25] G. Yilmaz, L. Messager, A. S. Gleinich, D. A. Mitchell, G. Battaglia, C. R. Becer, Polymer Chemistry 2016, 7, 6293. [26] J. Chiefari, Y. Chong, F. Ercole, J. Krstina, J. Jeffery, T. P. Le, R. T. Mayadunne, G. F. Meijs, C. L. Moad, G. Moad, Macromolecules 1998, 31, 5559.

[27] S. W. Prescott, M. J. Ballard, E. Rizzardo, R. G. Gilbert, Macromolecules 2002, 35, 5417.

[28] J. Zhang, J. Tanaka, P. Gurnani, P. Wilson, M. Hartlieb, S. Perrier, Polymer Chemistry 2017, 8, 4079.

[29] S. E. Shim, H. Lee, S. Choe, Macromolecules 2004, 37, 5565.

[30] C. Boyer, V. Bulmus, T. P. Davis, V. Ladmiral, J. Liu, S. Perrier, Chem. Rev. 2009, 109, 5402.

[31] K. Godula, M. L. Umbel, D. Rabuka, Z. Botyanszki, C. R. Bertozzi, R. Parthasarathy, J. Am. Chem. Soc. 2009, 131, 10263.

[32] J. I. Hare, T. Lammers, M. B. Ashford, S. Puri, G. Storm, S. T. Barry, Adv. Drug Delivery Rev. 2017, 108, 25.

[33] M. Hartmann, T. K. Lindhorst, Eur. J. Org. Chem. 2011, 2011, 3583.

[34] K. Kettler, K. Veltman, D. van de Meent, A. van Wezel, A. J. Hendriks, Environ. Toxicol. Chem. 2014, 33, 481.

[35] H. Ghazarian, B. Idoni, S. B. Oppenheimer, Acta Histochem. 2011, 113, 236.

[36] M. Köhn, J. M. Benito, C. Ortiz Mellet, T. K. Lindhorst, J. M. García Fernández, ChemBioChem 2004, 5, 771.

[37] G. Yilmaz, C. R. Becer, Eur. Polym. J. 2013, 49, 3046.

[38] C. Gerke, M. F. Ebbesen, D. Jansen, S. Boden, T. Freichel, L. Hartmann, Biomacromolecules 2017, 18, 787.

[39] Y. Abdouni, G. Yilmaz, C. R. Becer, Macromol. Rapid Commun. 2017.

[40] D. Appelhans, B. Klajnert-Maculewicz, A. Janaszewska, J. Lazniewska, B. Voit, Chem. Soc. Rev. 2015, 44, 3968.

[41] M. El Founi, S. M. A. Soliman, R. Vanderesse, S. Acherar, E. Guedon, I. Chevalot, J. Babin, J.-L. Six, J. Colloid Interface Sci. 2018, 514, 289.

[42] S. Won, S. Hindmarsh, M. I. Gibson, ACS Macro Letters 2018, 7, 178.

[43] G. Pasparakis, C. Alexander, Angewandte Chemie International Edition 2008, 47, 4847.

[44] R. Narain, S. P. Armes, Biomacromolecules 2003, 4, 1746.

[45] S. Qiu, H. Huang, X. H. Dai, W. Zhou, C. M. Dong, Journal of Polymer Science Part A: Polymer Chemistry 2009, 47. 
[46] S. Boye, D. Appelhans, V. Boyko, S. Zschoche, H. Komber, P. Friedel, P. Formanek, A. Janke, B. Voit, A. Lederer, Biomacromolecules 2012, 13, 4222.

[47] G. Yilmaz, E. Guler, C. Geyik, B. Demir, M. Ozkan, D. O. Demirkol, S. Ozcelik, S. Timur, C. R. Becer, Molecular Systems Design \& Engineering 2018.

[48] S. Peach, Macromolecules 1998, 31, 3372.

[49] C. P. Roe, Industrial \& Engineering Chemistry 1968, 60, 20.

[50] J. P. Rao, K. E. Geckeler, Prog. Polym. Sci. 2011, 36, 887.

[51] T. K. Dam, R. Roy, S. K. Das, S. Oscarson, C. F. Brewer, J. Biol. Chem. 2000, 275, 14223.

[52] Y. Gou, J. Geng, S. J. Richards, J. Burns, C. Remzi Becer, D. Haddleton, Journal of Polymer Science Part A: Polymer Chemistry 2013, 51, 2588. 